\title{
A hybrid approach of rough-fuzzy inference system for land degradation susceptibility mapping (case study: Khanmirza agricultural plain-Iran)
}

\author{
Mohammadreza Rezvani ${ }^{1}$, Hassanali Faraji Sabokbar ${ }^{* *}$, Shahabeddin Taghipour Javi ${ }^{2}$ and Hossein Nasiri ${ }^{1}$
}

\begin{abstract}
Background: Land degradation is considered a serious social, economic, and environmental issue in all parts of the world. The fight against this deleterious phenomenon is now an international priority. The mapping of land degradation entails the implementation of an analytical geospatial model to appraise and categorize the severity of land degradation across a region. This paper proposes a rough-fuzzy inference system (RFIS) for detect the most susceptibility area to land degradation. Rough set algorithm was employed to extract IF-THEN rules and fuzzy inference systems were applied in land degradation susceptibility mapping. We utilized this integrated approach to facilitate modeling of the susceptibility of areas to degradation in the Khanmirza agricultural plain in the southwest of Iran.

Results: The findings of the integrated approach revealed that $11.75 \%$ of the region faces high and very high susceptibility to land degradation, which is the major distribution in the central and marginal parts of the study area. The results of the present study indicates that those places have the lowest quality soil (erosion and ECs), and the lowlands are seriously menaced by degradation.

Conclusions: The evidence taken from field surveys confirmed the efficiency of the integrated approach for land degradation susceptibility mapping. The proposed approach can also produce more reasonable and understandable rules and superlative results in modeling the land degradation susceptibility.
\end{abstract}

Keywords: Land degradation, Rough set theory, Fuzzy inference system, GIS, Khanmirza agricultural plain

\section{Background}

Many aspects of our planet are changing rapidly due to pressure brought on by humans that has grown enormously during the last century causing habitat fragmentation, degradation, biodiversity loss, soil erosion and salinization, and water shortage (Basso et al. 2000; Change 2001; Ladisa et al. 2011; Salvati et al. 2013; Sepehr and Zucca 2012). These changes are expected to accelerate during the next decades, and many of them may cause the destruction of natural resources by altering livelihood support systems (Crutzen 2002; Jianchu et al. 2005; Metzger et al. 2006). Among these changes, land degradation is one of the most common and

\footnotetext{
* Correspondence: Hfaraji@ut.ac.ir

${ }^{1}$ Faculty of Geography, University of Tehran, Tehran, Iran

Full list of author information is available at the end of the article
}

serious environmental problems in the world. The concept of land degradation is widely used in the environmental sciences (Salvati and Carlucci 2010). It has already affected two billion hectares (22.5\%) of the world's agricultural land, pasture, forest, and woodland (Gao and Liu 2010). Severe land degradation is blamed for the disappearance of approximately 5-10 million ha of agricultural land annually, and it is threatening the wellbeing of over 250 million people, making it among the most pressing of contemporary environmental issues (Gao and Liu 2010; Reynolds et al. 2007; Wessels et al. 2012). Therefore, the fight against this deleterious phenomenon is now an international priority (Benabderrahmane and Chenchouni 2010; de Paz et al. 2006).

Many studies for the assessment and determination of land degradation have been conducted by many researchers 
in different areas, especially the Mediterranean (d'Angelo et al. 2000; de Paz et al. 2006; Ladisa et al. 2011; Maerker et al. 2008; Salvati et al. 2013; Sepehr et al. 2007; Vågen et al. 2013). Land degradation is mostly studied via methods such as field visits and remote sensing or Environmentally Sensitive Area Indexing (ESAI). For instance, Salvati et al. (2010 and 2013) used ESAI to determine land degradation in Italy, defined as a spatially delimited entity in which environmental and socio-economic factors are not sustainable for that particular environment. El Baroudy (2011), monitoring land degradation through remote sensing, assessed the causative factors, degree, and land degradation status using GIS techniques in the middle of the Nile Delta, Egypt. In addition, some researchers have used vegetation indices calculated from multi-year, notably advanced satellite data to monitor trends in primary productivity, for the purposes of assessing land degradation (Gao and Liu 2010; Wessels et al. 2012).

However, the mapping of land degradation entails the implementation of an analytical geospatial model to appraise and categorize the severity of land degradation across a region. Humphries et al. (2010) believed that the knowledge-based systems based on fuzzy logic networks provide many advantages and can accommodate the ambiguity and imprecision that may be involved in associating land attribute constraints with suitability. In the fuzzy inference system, when uncertain and imprecise data are used, the aggregation of dissimilar input variables is allowed in a consistent and reproducible way, and it has been applied in a wide range of science issues (Papadopoulos et al. 2011). Hence, it has recently attracted the attention of environmental scientists as suitable platforms for the evaluation of varying parameters related to environmental issues. For instance, Reshmidevi et al. (2009) used a fuzzy inference system developed in a GIS environment to assess land suitability for a specified crop, considering both land potential and surface water potential.

Fuzzy and rough sets are important techniques that can be used in various ways for modeling uncertainty in data and in spatial relationships between data entities. On the one hand, in the fuzzy inference system when uncertain and imprecise data are used, the aggregation of dissimilar input variables is allowed in a consistent and reproducible way, and it has been applied in a wide range of science issues (Papadopoulos et al. 2011). On the other hand, rough set theory is a powerful mathematical tool for analyzing various types of data and can be used in an attribute value representation model to describe the dependencies among attributes, evaluate the significance of attributes and derive decision rules (Zhang et al. 2014). Hence, it has recently attracted the attention of environmental scientists as suitable platforms for the evaluation of varying parameters related to environmental issues. For instance, Bittner \& Stell, (2002) consider rough sets for spatiotemporal data and how to discover characteristic configurations of spatial objects focusing on the use of topological relationships for characterizations. In a survey of uncertainty-based spatial data mining, Shi et al. (2003) provide a brief general comparison of fuzzy and rough set approaches for spatial data mining.

In this research, the Khanmirza agricultural plain in the southwest Iran has been selected as a study area due to its fragile physical conditions characterized by a traditional farming and the overexploitation of groundwater. Khanmirza agricultural plain is a typical area in the central mountain range of Zagros, Iran. It is also susceptible to land degradation and desertification due to the disregard of potential land sensitivity, the intensification of rural activities, and irrational development. Before the 1980s, the central region of Khanmirza plain (low flat ground) was generally covered in rich meadow lands, and the groundwater level was approximately 1 meter near the surface (Zagarell 1982). Recently, most areas in this region have lost land quality due to the sharp depletion of the aquifer and extensive human activities (Taghipour Javi et al. 2014). Therefore, land sensitivity coupled with extreme land use and groundwater quantity negative change may turn into an irreversible process of environmental degradation.

In this paper, a hybrid approach of rough set theory (RST) and fuzzy rule base inference system (FRBIS) coupled with a GIS environment is proposed for land degradation susceptibility mapping. In the present study a hybrid approach of RST and FRBIS is proposed based on local characteristics (variables and indicators related to groundwater and land quality and quantity) towards land degradation susceptibility mapping in the Khanmirza agricultural plain. The proposed approach combining roughfuzzy set theory along with GIS and remote sensing techniques have been applied to generate the final map.

\section{Study area description}

The Khanmirza agricultural plain is bounded by $50^{\circ} 58^{\prime}$ $51^{\prime \prime}$ and $51^{\circ} 11^{\prime} 16^{\prime \prime}$ E Longitude and $31^{\circ} 24^{\prime} 08^{\prime \prime}$ and $31^{\circ}$ $38^{\prime} 18^{\prime \prime} \mathrm{N}$ Latitude covering a total area of $257 \mathrm{Km}^{2}$ (Fig. 1). This area is located in the center of the central Zagros Mountains, which is a region with a complex topography located at the intersection of large-scale atmospheric circulations (Zaitchik et al. 2007). Major weather fronts affecting this area come from the Mediterranean Sea. Due to the direction of entry of the pluvial air masses, most of the moisture falls west of the Zagros Mountains. Minimal rainfall occurs in the eastern and central parts; consequently this situation also occurs in the Khanmirza Plain. Based on the synoptic weather station records, the annual average precipitation 


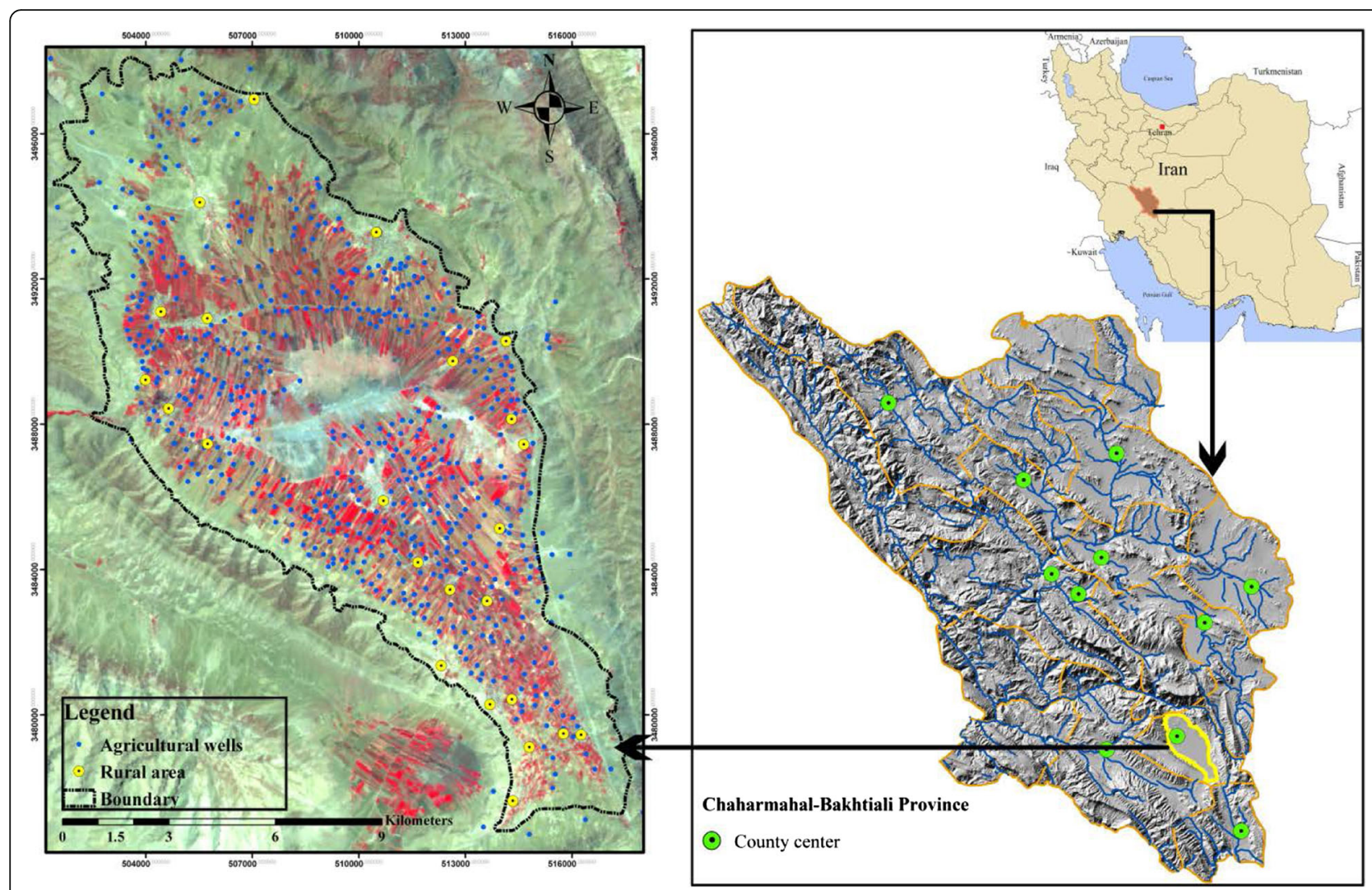

Fig. 1 Location of Khanmirza agricultural plain in Chaharmahal-Bakhtiari Province-Iran

for this plain is $587 \mathrm{~mm}, 90 \%$ of which occurs between December and April. The annual average maximum and minimum temperatures in this district are $29.51{ }^{\circ} \mathrm{C}$ and $3.42{ }^{\circ} \mathrm{C}$, respectively (Taghipour Javi et al. 2015).

This agricultural plain has 27 villages with a total population of about 30,000 persons as well as rich agricultural potential (Statistical Yearbook of Chaharmahal-Bakhtyari Province 2010). It is strongly affected by rural activities such as cultivation, which in the three past decades have dried up whole qanats, springs, and other surface water resources. Hence, farmers have focused thoroughly on groundwater resources as the most important water resources in this plain (Regional Water Company of Chaharmahal-Bakhtiari province 2010). The main available water resources for agricultural and drinking water purposes are about 1,000 deep wells (Fig. 1). Due to overexploitation of the confined aquifer, many agricultural wells have dried up, inasmuch as change in the groundwater levels were reduced an average of 15.82 meter in the last decade. On the other hand, irrigated agriculture land and meadow land were changed into rain-fed agriculture and bare land during this period (Taghipour Javi et al. 2014; Motiee Langroodi et al. 2015; Taghipour Javi et al. 2016). The number of agricultural wells and the groundwater overdraft in Khanmirza plain has added to the excessive pressure on aquifers, which has led to a reduction in land quality and, consequently, has adversely affected the environment in such ways as salt in groundwater resources and agricultural lands and land subsidence. Hence, the livelihood of more farmers living in this area is threatened by the degradation of arable farmland (Taghipour Javi et al. 2016).

\section{Methods \\ Data processing}

Land degradation is an interactive process involving multiple causal factors, among which climate variability, soil quality, and land management play a significant role (Bajocco et al. 2012; Rasmy et al. 2010; Shahbazi et al. 2009). It reduces soil fertility and is generally associated with geophysical conditions (e.g. climate, soil characteristics, slope, and vegetation cover) coupled with drought features (Salvati and Zitti 2008). In the Khanmirza agricultural plain, areas susceptible to degradation have generally been associated with particular conditions such as soil quality, topography, the status of vegetation cover, and quality and quantity of groundwater resources. The information and data sources for every one of the selected parameters are expressed in Table 1. The applied factors, including slope, normalized difference vegetation 
Table 1 Primary data layers used in the study

\begin{tabular}{lll}
\hline Factors & Raw data & Source \\
\hline NDVI changes & $\begin{array}{l}\text { TM images in June } \\
\text { 2000 and 2013 }\end{array}$ & Iranian Space Agency \\
Slope & $\begin{array}{l}\text { Topography map. } \\
1: 25,000\end{array}$ & $\begin{array}{l}\text { National Cartographic } \\
\text { Centre (NCC) }\end{array}$ \\
Water level changes & $\begin{array}{l}14 \text { piezometeric } \\
\text { wells in 2013 }\end{array}$ & $\begin{array}{l}\text { Regional Water Company of } \\
\text { Charmahal-Bakhtiari province }\end{array}$ \\
Soil erosion & Reports in 2009 & \\
IWQI & $\begin{array}{l}\text { Field Sampling } \\
\text { in July 2013 }\end{array}$ & Lab analysis \\
ECS & & \\
\hline
\end{tabular}

index (NDVI), groundwater level changes, soil erosion, irrigation water quality indicator (IWQI), and electrical conductivity of soil (ECs); were selected based on local conditions of the case study via field work, literature reviews, and experts' statements.

Land degradation is mainly linked to the change of vegetation cover. In this study, however, application of remote sensing (RS) has been limited to produce of the classification of Normalized Difference Vegetation Index (NDVI) map through the "density slice classification" in ENVI 4.5 environment. In the present study, vegetation cover changes between 2000 and 2013 were determined using multi-temporal satellite images. In order to compute vegetation cover changes, Landsat Thematic Mapper (TM) images (Path/Row 164 and 38) were used to extract the NDVI in June of the years 2000 and 2013. It is essential that TM images be pre-processed prior to calculating the NDVI and detecting change. It usually comprises a series of sequential operations, including atmospheric correction, geometric correction, and image enhancement. After the pre-processing step, the NDVI derived from the reflectance bands in the red and near-infrared range is a commonly accepted surrogate for vegetation cover based on reflectance in the visible and near-infrared spectra. For the TM images, NDVI was calculated as follows (Hansen \& Schjoerring, 2003):

$$
N D V I=N I R-R E D / N I R+R E D
$$

IWQI was generated with the associated parameters of electrical conductivity water $\left(\mathrm{EC}_{\mathrm{w}}\right)$, chloride $(\mathrm{Cl})$, and sodium adsorption ratio (SAR) suggested by Sepehr et al. 2007 and was also applied by Bakr et al. 2012 in the assessment of land sensitivity to desertification. The IWQI formula that has been utilized for the three aforementioned parameters is:

$$
I W Q I=\left(E C_{W} \times S A R \times C I\right)^{1 / 3}
$$

All parameters of $\mathrm{EC}_{\mathrm{w}}, \mathrm{Cl}$, and SAR (calculated by $\mathrm{Na}$ / $\left.((\mathrm{Ca}+\mathrm{Mg}) / 2)^{0.5}\right)$ were collected in 33 samplings from different irrigation sources in July 2013, and each sample was recorded using the global positioning system (GPS). In order to study soil quality, data regarding ECs were obtained from 35 soil samples, each of which was recorded using GPS in July 2013. The ECs was also determined conduct-metrically in the saturated soil paste extracted. In this study, we applied the detailed map of soil erosion that was generated using ETM+ images and ground sampling by Forest Range and Watershed Management Organization of Iran. The vector map was converted to the raster format in Arc GIS 9.3 software in order to use in the proposed model.

In this research takes advantage of continuous spatial data because in the common classification of spatial data, we will witness the loss of a significant amount of information. On the other hand, in order to run the proposed model, it was necessary to be taken advantage of continuous data because the fuzzy approach used to reduce the uncertainties that exist in the classic methods of data classification. This interpolation approach is applied by Kriging, which is the best unbiased linear estimator of water resources (Moukana and Koike 2008; Märker et al. 2008, Motiee Langroodi et al. 2015). Therefore, all of the ECs sample and piezometric data were interpolated using the Kriging method in order to obtain regional distribution and spatial coverage.

\section{Fuzzy rule-based inference system (FRBIS)}

Fuzzy logic, introduced by Zadeh (1965), is a powerful tool for decision making that applies linguistic terms to provide an inference structure for modeling complex structures. A fuzzy set is a general form of a crisp set that belongs to the closed interval 0 and 1; where 1 addresses full membership and 0 expresses non-membership (Yazdani-Chamzini et al. 2013; Yazdani-Chamzini and Yakhchali 2012). There are three widely used types of fuzzy inference systems: Mamdani, Sugeno, and Tsukamoto (Mamdani and Assilian 1975; Takagi and Sugeno 1985; Tsukamoto 1979). The basic difference between the various models lies in the representation of the consequence of their fuzzy rules. Accordingly, the aggregation and defuzzification procedures of the three models are different. In this paper, the Mamdani model was be utilized as one of the most popular algorithms. This method uses the concepts of fuzzy sets and fuzzy logic to translate an entirely unstructured set of linguistic heuristics into an algorithm (Mamdani and Assilian 1975). In the current study, we carried out four steps of FRBIS;

The First Step in FRBIS is fuzzification in which the process of transferring crisp values into fuzzy if-then rules is implemented through grades of membership for linguistic variables of fuzzy sets. Indeed, input parameter was translated into linguistic terms, such as very high, high, moderate, and low. This process was performed with the help of membership function (MF). These MFs 
have different types of linear and nonlinear shapes. The second step in the FRBIS approach was the definition of the rules, the core of the inference system, which connects the input with the output. The database and rulebase-form knowledge base, which the fuzzy sets' MFs applied in generating the fuzzy rules, are defined by the database and fuzzy if-then rules. The input-output relationships were defined by fuzzy conditional functions that are known as fuzzy "if-then" rules. A fuzzy conditional rule is generally made up of a premise (antecedent) and a consequence (conclusion) part. Fuzzy inference system is the main phase of a fuzzy expert system that aggregates the facts derived from the fuzzification process with the rule base generated in the previous part and conducts the modeling process (Yazdani-Chamzini et al. 2013). In the present study, the Mamdani fuzzy model has been applied as one of the most applicable algorithms. Different fuzzy composition methods can be used to establish the Mamdani fuzzy model. The maximum-minimum composition, the most commonly used method (Ross 2009), was utilized in this study. This technique is mathematically defined as follows (Monjezi and Rezaei 2011):

$$
\mu_{B^{k}}(Z)=\max _{k}\left[\min \left[\mu_{A_{1}^{k}}\left(I_{1}\right), \mu_{A_{2}^{k}}\left(I_{2}\right)\right]\right] ; \quad k=1,2, \ldots, r
$$

where $\mu_{B^{k}}, \mu_{A_{1}^{k}}$, and $\mu_{A^{k}}$ are the membership functions of output " $Z$ " for rule " $k$ ", input " $I_{1}$ ", and " $I_{2}$ ", respectively. In the present study, centroid of area (COA) method was applied for the defuzzification process. The advantage of the COA method is that all activated membership functions of the conclusions (all active rules) take part in the defuzzification process (Daftaribesheli et al. 2011). The COA method applies the following equation to transfer a fuzzy scheme into a crisp value (Iphar and Goktan 2006):

$$
Z^{*}=\frac{\int \mu_{\tilde{c}}(z) \cdot \mathrm{zdz}}{\int \mu_{\tilde{c}}(z) \mathrm{dz}}
$$

where $\mathrm{Z}$ " is the crisp value for the "z" output and $\mu_{\tilde{c}}(\mathrm{z})$ is the aggregated output membership function.

\section{Rough set theory (RST)}

Rough set theory, introduced by Pawlak in 1982, provides a novel data-mining tool that deals with vagueness and uncertainty for identifying cause-effect relationships in a database or information system. (Pawlak 1982; Pawlak and Skowron 2007). The basis of RST is the indiscernibility relation, which is generated by information about objects of interest. An indiscernibility relation is a relation between two or more objects, where all the values are identical in relation to a subset of considered attributes (Ponce and Karahoca 2009). In the other words, principal assumption of RST is based on the concept that with every associated object of the universe of discourse, some information objects characterized by the same information are indiscernible in the view of the available information about them. Any set of all indiscernible objects is called an elementary set and forms a basic granule of knowledge about the universe. Any union of elementary sets is referred to as a precise set; otherwise the set is rough (Cheng et al. 2010).

The approximations are two basic operations in RST (Pawlak 2001). Suppose we are given two finite and nonempty sets $\mathrm{U}$ and $\mathrm{A}, \mathrm{U}$ is called the universe and $\mathrm{A}$ is a set of attributes. With attributes $a \in A$ we associate a set $\mathrm{V}_{\mathrm{a}}$ (value set) called the domain of a. Any subset B of A determines a binary relation IND (B) on U which will be called an indiscernibility relation (Komorowski et al. 1998):

$$
\operatorname{IND}(B)=\{(x, y) \in U \mid \forall a \in B, \mathrm{a}(\mathrm{x})=\mathrm{a}(\mathrm{y})\},
$$

where: $\operatorname{IND}(B)$ is an equivalence relation and is called Bindiscernibility relation. If $(x, y) \in I N D(B)$, then $\mathrm{x}$ and $\mathrm{y}$ are B-indiscernible (indiscernible from each other by attributes from $\mathrm{B})$. The equivalence classes of the $\mathrm{B}$ indiscernibility relation will be denoted $\mathrm{B}(\mathrm{x})$.

The indiscernibility relation will be used now to define basic concept of RST. Let Information System be define (1) and let $B \quad A$ and $X \quad U$. We can approximate X using only the information contained in B by constructing lower approximation and upper approximation of $\mathrm{X}$ on the following way:

$$
\begin{aligned}
& \underline{B}(X)=\{x \in U: B(x) \subseteq X\} \\
& \bar{B}(X)=\{x \in U: B(x) \cap X \neq \varnothing\}
\end{aligned}
$$

The lower approximation consists of all objects that definitely belong to the set, and the upper approximation

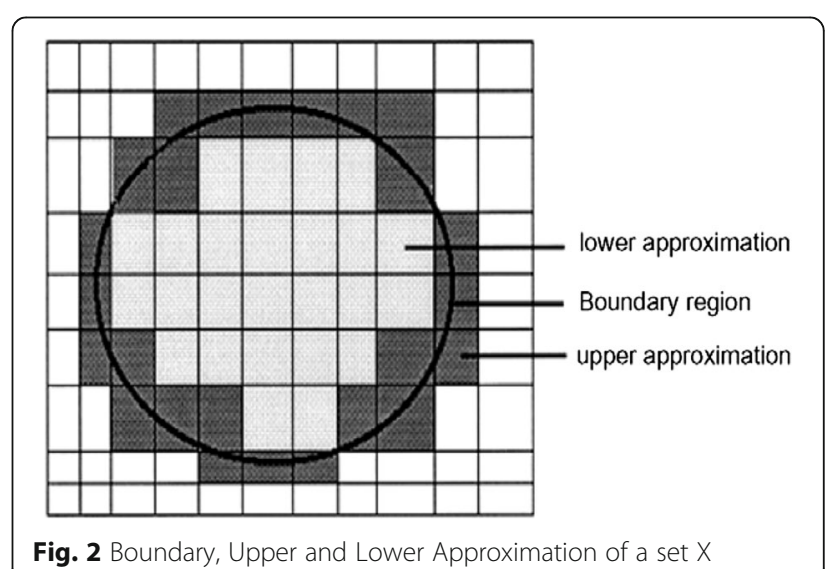


contains all objects that possibly belong to the set. The difference between the upper and the lower approximation composes the boundary region of the rough sets (Pawlak 2001; Pavel and Jiří 2007).

$$
B N_{B}(X)=\bar{B}(X)-\underline{B}(X)
$$

The boundary region of $\mathrm{X}$ consist those objects that we cannot decisively classify into $\mathrm{X}$ on the basis of knowledge $\mathrm{B}$. The set $\mathrm{X}$ is called "rough" with respect to the knowledge in $\mathrm{B}$, if the boundary region is nonempty. The basic concepts in rough sets are shown in Fig. 2.

The RST is a series of logical reasoning procedures used for analyzing an information system. An information system can be seen as a decision table, denoted by $S=(U$, $A, C, D)$, where $\mathrm{U}$ is the universe of discourse, $\mathrm{A}$ is a set of primitive features, and $C$; $D \subset A$ are two subsets of features, assuming that $A=(C \cup D)$ and $C \cap D=\varnothing$, where $C$ is called the condition attribute and $\mathrm{D}$ is the decision attribute. The measure to describe the inexactness of approximation classifications is called the quality of approximation of $\mathrm{X}$ by $\mathrm{B}$. It expresses the percentage of objects that can be correctly classified into class $\mathrm{X}$, employing the attribute B (Pawlak 1982; Cheng et al. 2010):

$$
\gamma_{B}(A)=\frac{\sum \operatorname{card} \underline{B}\left(X_{i}\right)}{\operatorname{card}(U)}
$$

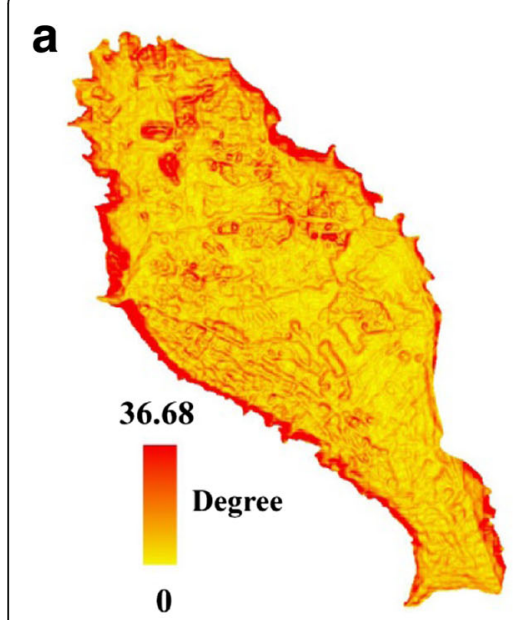

Slope

d

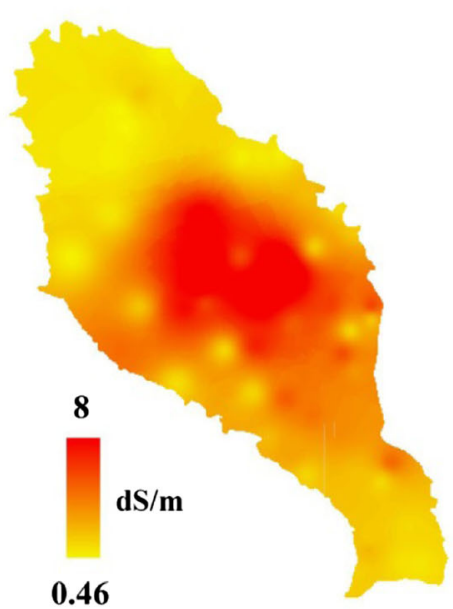

Electrical Conductivity of Soil

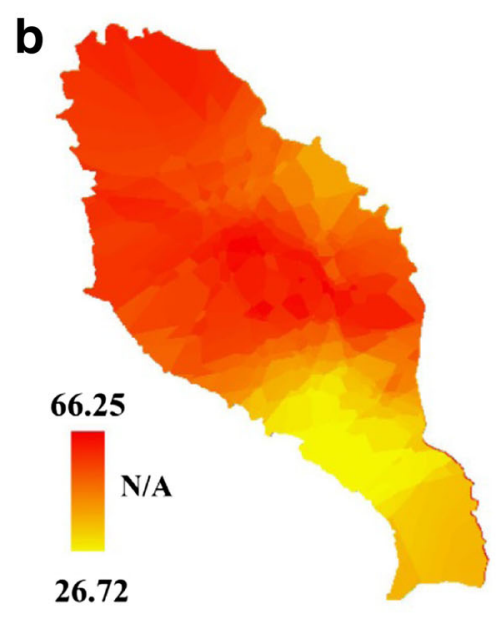

Soil Erosion

e

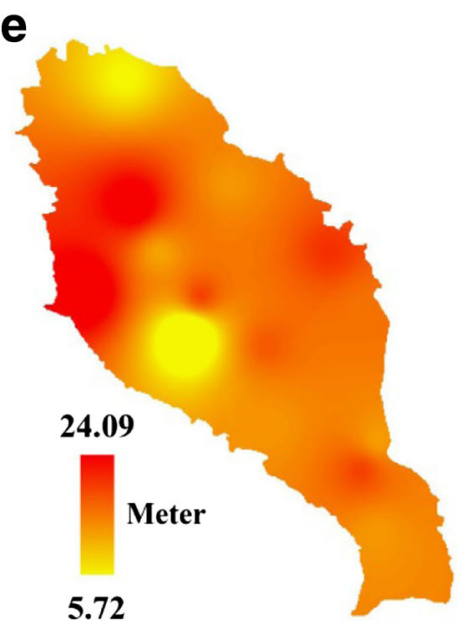

Groundwater Level Changes

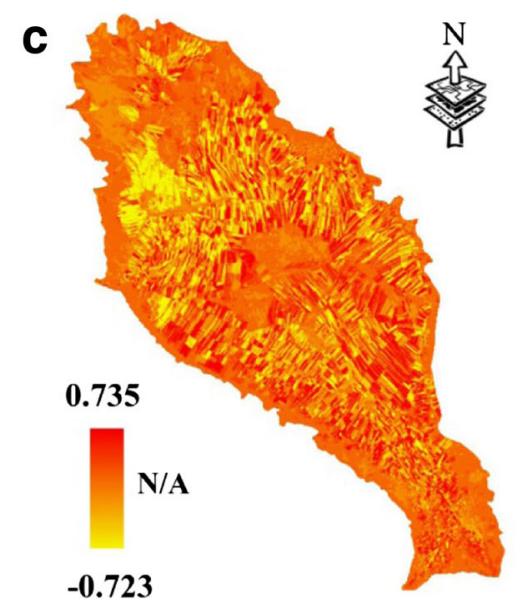

$-0.723$

\section{Vegetation Cover Changes}

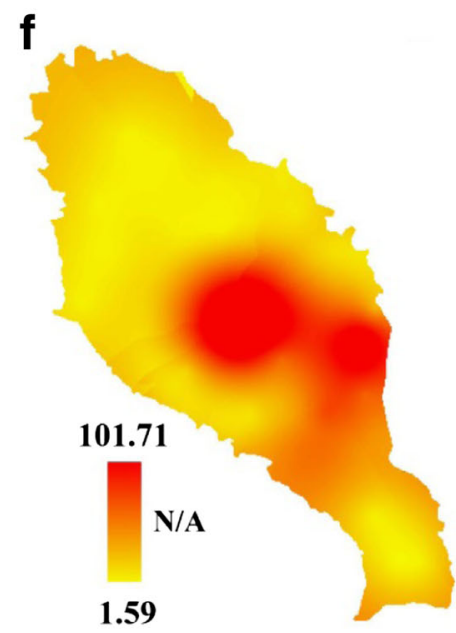

Irrigation Water Quality Indicator

Fig. 3 Maps as input data layers into the RFIS model. a Slope, b Soil Erosion, c Vegetation Cover Changes, d Electrical Conductivity of Soil, e Groundwater Level changes, f Irrigation Water Quality Indicator 
If $\gamma_{B}(A)=1$, then the decision table is consistent; otherwise, it is inconsistent.

An important subject in RST is attribute reduction in which the reduced set of attributes provides the same quality of approximation as the original set. There are two basic concepts in connection with this attribute reduction. The Breduct of A, denoted by RED (B), is the minimal subset of $A$, which provides the same quality of approximation of objects into elementary classes of $B$ as the whole attributes of A. The B-core of A, CORE (B), is the necessary part of $A$, which cannot be eliminated without disturbing the ability to classify objects into the elementary classes of B (Pawlak 1982). It is the intersection of all reducts.

$$
\operatorname{CORE}(B)=\underset{R_{i} \in \operatorname{RED}(B)}{\cap}, i=1,2, \ldots
$$

Using a reduced algorithm, the rules can be found through determining the decision attributes value, based on the condition attributes values. Therefore, the rules are showed in an "IF condition(s) THEN decision(s)" format. The concept of the decision table is used in this study to create rules from fuzzy relationships, which generate rules for better reaching results.

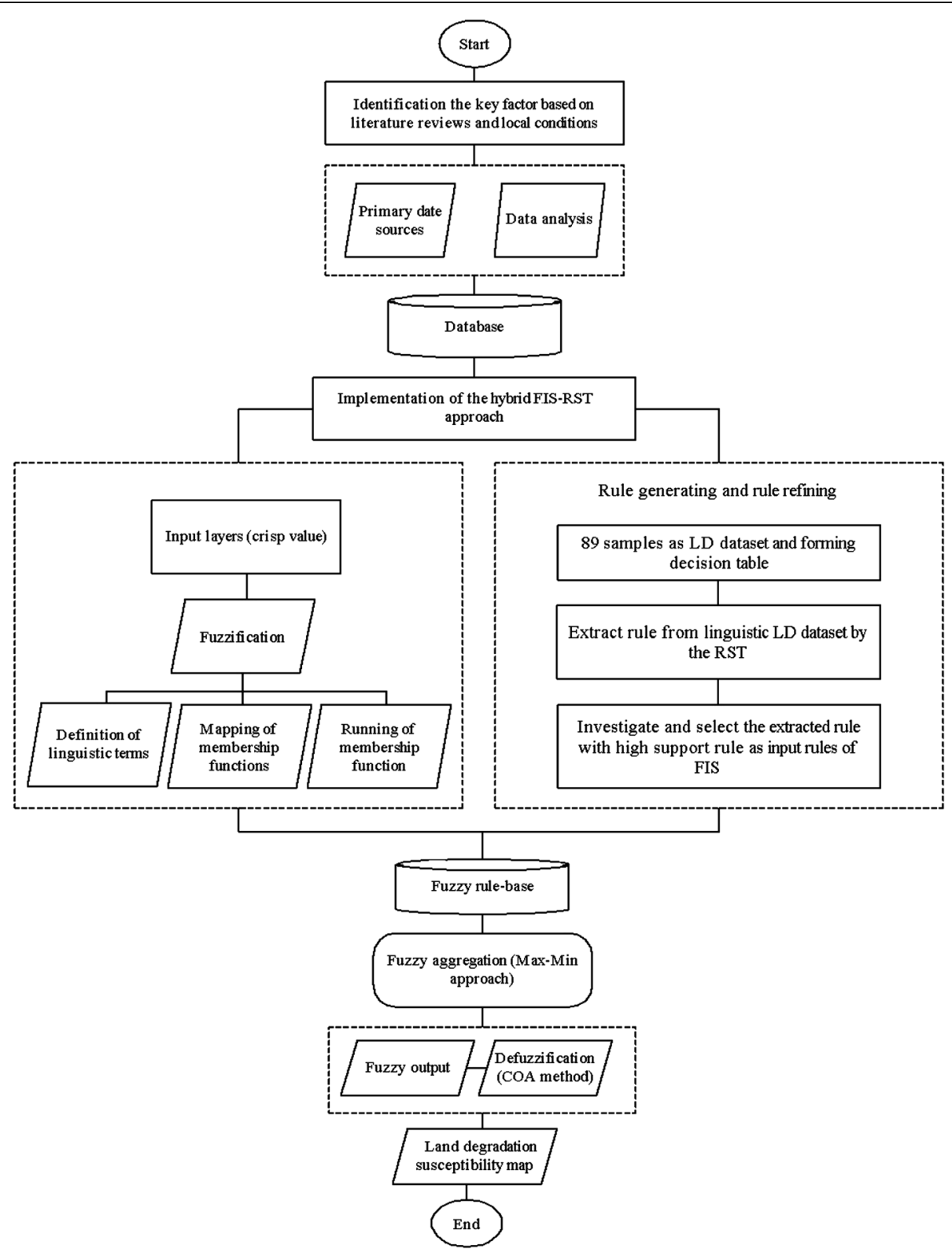

Fig. 4 A model of RFIS for identifying potential areas of land degradation 


\section{Results and discussion}

\section{Layers analysis of the study area}

Topographically the study area is in the elevation range of 1827 to $2005 \mathrm{~m}$ above sea level based upon the digital elevation model, and the slope gradient varies from 0 to $\sim 37^{\circ}$ (Fig 3a). In the study area, land sensitivity to soil erosion extends beyond the borders of agricultural lands into bare areas and patches along the edges of meadow lands in the vicinity of agricultural lands. Owing to the high gradient and less vegetation cover, the highest sensitivity to erosion was observed in the low-lands and in the northern and western margins of the region (Fig 3b). The results of the NDVI change showed that this region is faced with remarkable variations in vegetation cover. According to the NDVI change map in Fig. 3c, most cover changes have occurred around the northwestern and central parts of the Plain, where there are rain-fed agricultural and meadow lands.

Owing to the high saline water, salinization, and other forms of chemical damage to the soil emerged in the central regions. Therefore, according to the ECs map (Fig. 3d) we observed that the highest salinity of soil ranging $\sim 4$ to $\sim 8 \mathrm{dS} / \mathrm{m}$ was centralized in the center of the Plain. Additionally, runoff has created rill erosion in the agricultural lands near the marginal meadow during the spring months of every year when the soils are usually saturated and vegetative cover is minimal. In the last decade, however, government policies encouraged farmers to expand irrigated lands in the margin and center of the plain and it has caused an increase in agricultural wells. Consequently, in this part of the study area, the groundwater level decreased by $\sim 16.2$ to $\sim 17.4 \mathrm{~m}$ in 2000 to 2013 (Fig 3e). Whereas the dominant meadow species from an ecological aspect is completely dependent on water resources, thus, in response to a sharp drop in water resources, the area of meadow lands has been drastically reduced. According to Fig 3f, the IWQI map results indicate the lowest irrigated water quality, 17 to 102 , has occurred in the lowlands

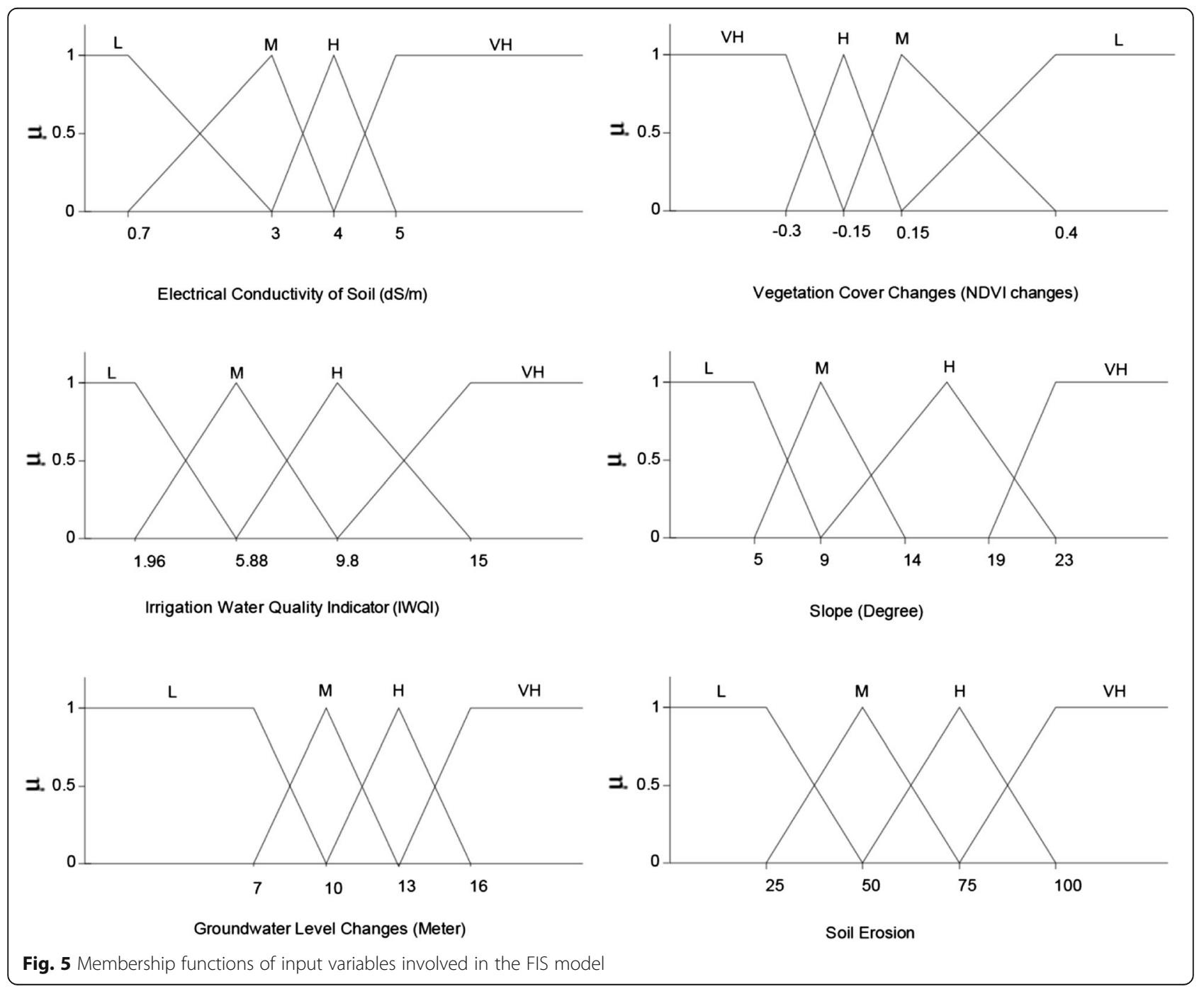


Table 2 Collected If-Then rules with the different degrees of land degradation

\begin{tabular}{|c|c|c|c|c|c|c|c|c|c|c|c|c|c|c|c|}
\hline No & NDVI & $\mathrm{EC}$ & Slope & IWQI & ChangeLevel & Erosion & Decision & No & NDVI & EC & Slope & IWQI & ChangeLevel & Erosion & Decision \\
\hline 1 & Moderate & Low & Very High & Low & Moderate & Moderate & High & 46 & Moderate & Moderate & Low & Moderate & Moderate & Low & Moderate \\
\hline 2 & Moderate & Low & Very High & Low & Moderate & Moderate & High & 47 & Moderate & Moderate & Low & Moderate & Moderate & Low & Moderate \\
\hline 3 & Very High & Moderate & Low & Moderate & Very High & Moderate & High & 48 & High & Moderate & Very Low & Moderate & Moderate & Low & Moderate \\
\hline 4 & Very High & Moderate & Moderate & Moderate & Moderate & Moderate & High & 49 & Very High & Moderate & Very Low & Moderate & Moderate & Moderate & Moderate \\
\hline 5 & High & Very Low & High & Very Low & Very High & Moderate & High & 50 & Very High & Moderate & Very Low & Moderate & Low & Moderate & Moderate \\
\hline 6 & Moderate & Very Low & Very High & Very Low & High & High & High & 51 & Very High & Moderate & Low & Moderate & Moderate & Moderate & Moderate \\
\hline 7 & Moderate & High & Low & Very High & Moderate & Very Low & High & 52 & Very High & Moderate & Low & Moderate & Moderate & Moderate & Moderate \\
\hline 8 & Low & Moderate & Very Low & Very High & Moderate & High & High & 53 & Very High & Moderate & Low & Moderate & Moderate & Moderate & Moderate \\
\hline 9 & Very Low & High & Very Low & Moderate & Low & Very Low & Low & 54 & Low & Moderate & Low & Moderate & Very High & Moderate & Moderate \\
\hline 10 & Low & Low & Low & Moderate & High & Low & Low & 55 & High & Moderate & Very Low & Moderate & Mo & Mc & Mc \\
\hline 11 & Low & Moderate & Low & Moderate & Moderate & Low & Low & 56 & High & Moderate & Low & Moderate & High & Moderate & Moderate \\
\hline 12 & Low & Moderate & Very Low & Moderate & Moderate & Low & Low & 57 & Low & Moderate & Low & Moderate & High & Moderate & Moderate \\
\hline 13 & Moderate & Low & Low & Very Low & Low & Low & Low & 58 & Moderate & Moderate & Low & Moderate & High & Moderate & Moderate \\
\hline 14 & High & Moderate & Low & Very Low & Low & Low & Low & 59 & High & Moderate & Very Low & Moderate & High & Moderate & Moderate \\
\hline 15 & Low & Moderate & Low & Very Low & Very Low & Low & Low & 60 & Moderate & Moderate & High & Moderate & High & Moderate & Moderate \\
\hline 16 & Very Low & Moderate & Low & Very Low & Moderate & Moderate & Low & 61 & Very High & Moderate & Low & Moderate & Moderate & Moderate & Moderate \\
\hline 17 & Moderate & Very Low & Low & Very Low & Very Low & Moderate & Low & 62 & Moderate & Moderate & Low & Moderate & Low & Moderate & Moderate \\
\hline 18 & Moderate & Moderate & Moderate & Very Low & Very Low & Moderate & Low & 63 & High & Low & Low & Very Low & Very High & Moderate & Moderate \\
\hline 19 & Moderate & Very Low & Moderate & Very Low & Moderate & Moderate & Low & 64 & Moderate & Low & Moderate & Very Low & Very High & Moderate & Moderate \\
\hline 20 & Moderate & Very Low & Very Low & Very Low & Low & Moderate & Low & 65 & Moderate & Very Low & Very High & Very Low & Moderate & Moderate & Moderate \\
\hline 21 & Very Low & Moderate & Moderate & Very Low & Very Low & Moderate & Low & 66 & Moderate & Low & Low & Very Low & Very High & Moderate & Moderate \\
\hline 22 & Moderate & Very Low & Moderate & Very Low & Moderate & Moderate & Low & 67 & Moderate & Low & Low & Very Low & Very High & Moderate & Moderate \\
\hline 23 & Moderate & Very Low & Moderate & Very Low & High & Moderate & Low & 68 & Moderate & Low & Moderate & Very Low & Moderate & Moderate & Moderate \\
\hline 24 & Moderate & Very Low & Low & Very Low & Moderate & Moderate & Low & 69 & Moderate & Low & High & Very Low & Mod & High & Mode \\
\hline 25 & Moderate & Low & Low & Very Low & High & Moderate & Low & 70 & High & Low & Low & Very Low & Moderate & High & Moderate \\
\hline 26 & Moderate & Low & Low & Very Low & High & Moderate & Low & 71 & Low & Low & Moderate & Very Low & Moderate & Very High & Moderate \\
\hline 27 & Low & Low & Low & Very Low & Moderate & Moderate & Low & 72 & Very High & Moderate & Moderate & Low & High & Very High & Very High \\
\hline 28 & High & Low & Low & Low & Moderate & Moderate & Moderate & 73 & Very High & Very High & Low & High & Low & Very Low & Very High \\
\hline 29 & Moderate & Low & Low & Low & Moderate & Moderate & Moderate & 74 & Very High & Moderate & Very Low & High & Moderate & Moderate & Very High \\
\hline 30 & L & Moderate & Low & Low & Low & Moderate & Moderate & 75 & Moderate & High & Low & Moderate & Very High & Low & Very High \\
\hline 31 & Moderate & Moderate & Moderate & Low & Moderate & Moderate & Moderate & 76 & Moderate & Low & Very High & Moderate & High & Very High & Very High \\
\hline 32 & High & Low & Low & Low & Moderate & Moderate & Moderate & 77 & Very High & Very High & Very Low & Very High & Moderate & Very Low & Very High \\
\hline
\end{tabular}


Table 2 Collected If-Then rules with the different degrees of land degradation (Continued)

\begin{tabular}{|c|c|c|c|c|c|c|c|c|c|c|c|c|c|c|c|}
\hline 33 & Moderate & Low & Low & Low & Moderate & Moderate & Moderate & 78 & Moderate & Very High & Low & Very High & Moderate & Very Low & Very High \\
\hline 34 & Moderate & Low & High & Low & Moderate & Moderate & Moderate & 79 & Moderate & Very High & Very Low & Very High & Moderate & Very Low & Very High \\
\hline 35 & Moderate & Moderate & Low & Low & Low & High & Moderate & 80 & Very High & Very High & Very Low & Very High & High & Very Low & Very High \\
\hline 36 & Moderate & Very Low & Moderate & Low & Moderate & Very High & Moderate & 81 & Moderate & High & Very Low & Very High & Very High & Very Low & Very High \\
\hline 37 & Moderate & High & Very Low & High & Moderate & Very Low & Moderate & 82 & Very Low & Low & Low & Moderate & Very Low & Moderate & Very Low \\
\hline 38 & Moderate & High & Low & High & Moderate & Very Low & Moderate & 83 & Very Low & Low & Low & Very Low & Very Low & Low & Very Low \\
\hline 39 & Moderate & High & Very Low & High & Low & Very Low & Moderate & 84 & Very Low & Low & Low & Very Low & Very Low & Low & Very Low \\
\hline 40 & Moderate & High & Low & High & Moderate & Very Low & Moderate & 85 & Moderate & Very Low & Moderate & Very Low & Very Low & Low & Very Low \\
\hline 41 & Moderate & High & Very Low & High & Low & Low & Moderate & 86 & Very Low & Low & Low & Very Low & Very Low & Low & Very Low \\
\hline 42 & Moderate & High & Very Low & High & Moderate & Moderate & Moderate & 87 & Low & Very Low & Very Low & Very Low & Very Low & Moderate & Very Low \\
\hline 43 & High & Moderate & Low & High & Moderate & Moderate & Moderate & 88 & Very Low & Very Low & Low & Very Low & Very Low & Moderate & Very Low \\
\hline 44 & High & Very High & Low & Moderate & Moderate & Very Low & Moderate & 89 & Very Low & Low & Very Low & Very Low & Low & Moderate & Very Low \\
\hline 45 & Low & High & High & Moderate & Moderate & Low & Moderate & & & & & & & & \\
\hline
\end{tabular}


(central parts). As a result, based on the aforementioned conditions, the central parts of the study area cannot withstand the aggregated effects without a significant reduction in the quality of resources. All spatial layers have been applied into the hybrid approach to indicate the most affected area by land degradation phenomenon in the Khanmirza agricultural plain.

\section{Hybrid approach of RST and FRBIS}

The overall process of land degradation susceptibility mapping using an integrated model of RST and FRBIS has been schematically presented in Fig. 4 . The collected data related to the six factors were analyzed in the present study. Having collected the information layers according to the diagram, the six input layers were converted into the raster format with a pixel size of $50 \times 50 \mathrm{~m}$ in the GIS environment in order to implement a hybrid approach of RST and FRBIS, and the primary spatial analyses were performed on them. Following this, the integrated model based on the Mamdani algorithm was implemented on the fuzzy logic toolbox of MATLAB software.

Here, the attributes measured on different scales were converted into a common range $[0,1]$, depending on the degree of truth of the respective suitability parameters. Then, the MFs were defined to associate the four linguistic variables, Low $(\mathrm{L})$, Moderate $(\mathrm{M})$, High $(\mathrm{H})$, and Very High (VH). Figs. 5 represent the MFs related to the six aforementioned parameters as the input layers and susceptibility to land degradation. Values and intervals in each of MFs associated with linguistic terms were defined based on the field survey and experts' judgment.

Next, the fuzzy if-then rules based on the rough set algorithm were constructed. In fact, the FRBIS and RST are integrated in the step, named as IF-THEN Rules extraction step. These rules represent the fuzzy relations between input and output variables. In order to composite fuzzy relations, the min-max composition method was applied. The extraction of IF-THEN rules in the FRBIS is always a challenging issue and is highly affected by the knowledge and skillfulness of the decision maker. Accordingly, modeling using a RST to produce rules can overcome the limitations of statistical methods and the produced "if-then" rules can model the qualitative aspects of human knowledge applicable for decision makers. In the other words, a rough set algorithm is one proper data mining algorithm suggested to extract logical rules from complex spatial data. Making a decision table is a prerequisite for knowledge analysis using a RST. In this paper, the decision table was established using six condition attributes (slope, soil erosion, water level changes, IWQI, ECs, and NDVI changes) and one decision attribute (from the low susceptibility to the very high susceptibility) to indicate the degree of land degradation susceptibility. In order to prepare the decision table, 89 samples were collected with the different degrees of land degradation using field survey. These samples indicated in Table 2. The RST was performed to extract the IF -THEN rules by JMAF software.

The most important results of data analysis using the rough set theory are reduct sets and core attributes. The reduct sets are the shortest possible combinations of condition attributes (independent) which can demonstrate changes in the decision attribute (dependent) with the same accuracy. In other words, it is possible to determine the land degradation susceptibility by consideration these attributes as same accuracy as consideration all attributes. Table 3 illustrates the reduct sets and core attributes as results of RST implementation. The rough set theory presents two attributes slope and ECs as core variables. Core attributes are variables which exist in all reduct set. Indeed, it is not possible to forecast the changes in the decision attribute without using electrical conductivity of soil and slope.

Next step utilizes the algorithms of RST to mine rules from the decision table. The generated rules are in the form of "if-then" with specific condition attribute values and a decision attributes value. There are two operations involved in this phase, as follows: rule generation and rule refining. This procedure applies the RST to extract IF-Then rules from the linguistic land degradation datasets, and to refine the extracted rules through remove the rules with low support value for FRBIS implementation. The rule base generated by RST, compromising 38 rules, describes the various contributions of these factors on the degree of susceptibility. These rules are listed in Table 4.

Finally, the defuzzification process was utilized to convert fuzzy values into crisp values. Five linguistic values are defined on the degree of susceptibility from A (very high) to E (not susceptible) as shown in Fig. 6. Furthermore, the degree of susceptibility to land degradation was classified, and the final susceptibility map was prepared.

Figure 7 depicts the final result of the integrated method for land degradation susceptibility area. In this

Table 3 Presentation of core attributes and reducts sets using RST

\begin{tabular}{ll}
\hline Name & Content \\
\hline Core attributes & Slope and Electrical Conductivity of Soil \\
Reduct sets & NDVI, Slope, IWQI, Erosion, Water Level \\
& Changes, ECs \\
& NDVI Change, ECs, Slope, IWQI, \\
& Soil Erosion \\
& NDVI Change, ECs, Slope, Soil Erosion, \\
& Water Level Changes \\
& ECs, Slope, Soil Erosion, Water Level Changes \\
\hline
\end{tabular}


Table 4 Refined If-Then rules from the linguistic land degradation datasets via RST using JMAF software for FIS implementation

\begin{tabular}{|c|c|c|c|c|c|c|c|c|c|c|c|c|c|c|c|c|c|c|c|c|}
\hline No & & Content & & LV & & Content & & LV & & Content & & & & Content & & & Then & LD Susceptibility & $\mathrm{LV}^{\mathrm{a}}$ & \\
\hline 1 & If & (EC & $>=$ & Very high) & $\&$ & (IWQI & $>=$ & High) & & & & & & & & & $\Rightarrow>$ & (Decision & $>=$ & $\overline{\text { Very high) }}$ \\
\hline 2 & If & (ChangeLevel & $>=$ & High) & \& & (Erosion & $>=$ & Very high) & & & & & & & & & $\Rightarrow>$ & (Decision & $>=$ & Very high) \\
\hline 3 & If & (NDVI & $>=$ & Very high) & \& & (IWQI & $>=$ & High) & & & & & & & & & $=>$ & (Decision & $>=$ & Very high) \\
\hline 4 & If & (EC & $>=$ & High) & $\&$ & (ChangeLevel & $>=$ & Very high) & & & & & & & & & $\Rightarrow>$ & (Decision & $>=$ & Very high) \\
\hline 5 & If & (IWQI & $>=$ & Very high) & & & & & & & & & & & & & $\Rightarrow>$ & (Decision & $>=$ & High) \\
\hline 6 & If & (EC & $>=$ & Low) & $\&$ & (Slope & $>=$ & Very high) & & & & & & & & & $\Rightarrow>$ & (Decision & $>=$ & High) \\
\hline 7 & If & (Slope & $>=$ & Very high) & $\&$ & (ChangeLevel & $>=$ & High) & & & & & & & & & $\Rightarrow>$ & (Decision & $>=$ & High) \\
\hline 8 & If & (NDVI & $>=$ & Very high) & \& & (ChangeLevel & $>=$ & High) & & & & & & & & & $\Rightarrow>$ & (Decision & $>=$ & High) \\
\hline 9 & If & (NDVI & $>=$ & Very high) & \& & (Slope & $>=$ & Moderate) & & & & & & & & & $=>$ & (Decision & $>=$ & High) \\
\hline 10 & If & (NDVI & $>=$ & High) & $\&$ & (Slope & $>=$ & High) & & & & & & & & & $=>$ & (Decision & $>=$ & High) \\
\hline 11 & If & (Slope & $>=$ & High) & & & & & & & & & & & & & $\Rightarrow>$ & (Decision & $>=$ & Moderate) \\
\hline 12 & If & (ChangeLevel & $>=$ & Very high) & & & & & & & & & & & & & $=>$ & (Decision & $>=$ & Moderate) \\
\hline 13 & If & (NDVI & $>=$ & High) & \& & (ChangeLevel & $>=$ & Moderate) & & & & & & & & & $=>$ & (Decision & $>=$ & Moderate) \\
\hline 14 & If & (NDVI & $>=$ & Moderate) & $\&$ & (IWQI & $>=$ & Low) & & & & & & & & & $\Rightarrow>$ & (Decision & $>=$ & Moderate) \\
\hline 15 & If & (NDVI & $>=$ & Low) & \& & (IWQI & $>=$ & Low) & $\&$ & (Erosion & $>=$ & Moderate) & & & & & $=>$ & (Decision & $>=$ & Moderate) \\
\hline 16 & If & (EC & $>=$ & Low) & \& & (Slope & $>=$ & Moderate) & $\&$ & (ChangeLevel & $>=$ & Moderate) & & & & & $=>$ & (Decision & $>=$ & Moderate) \\
\hline 17 & If & (ChangeLevel & $>=$ & Moderate) & & & & & & & & & & & & & $\Rightarrow>$ & (Decision & $>=$ & Low) \\
\hline 18 & If & (EC & $>=$ & Moderate) & & & & & & & & & & & & & $\Rightarrow>$ & (Decision & $>=$ & Low) \\
\hline 19 & If & (NDVI & $>=$ & Moderate) & \& & (ChangeLevel & $>=$ & Low) & & & & & & & & & $\Rightarrow>$ & (Decision & $>=$ & Low) \\
\hline 20 & If & (NDVI & $>=$ & Moderate) & \& & (Erosion & $>=$ & Moderate) & & & & & & & & & $\Rightarrow>$ & (Decision & $>=$ & Low) \\
\hline 21 & If & (NDVI & $<=$ & Very low) & \& & (EC & $<=$ & Low) & & & & & & & & & $=>$ & (Decision & $<=$ & Very low) \\
\hline 22 & If & (Slope & $<=$ & Very low) & \& & (ChangeLevel & $<=$ & Very low) & & & & & & & & & $=>$ & (Decision & $<=$ & Very low) \\
\hline 23 & If & (EC & $<=$ & Very low) & $\&$ & (Erosion & $<=$ & Low) & & & & & & & & & $=>$ & (Decision & $<=$ & Very low) \\
\hline 24 & If & (ChangeLevel & $<=$ & Very low) & & & & & & & & & & & & & $=>$ & (Decision & $<=$ & Low) \\
\hline 25 & If & (NDVI & $<=$ & Low) & \& & (Slope & $<=$ & Low) & $\&$ & (Erosion & $<=$ & Low) & & & & & $=>$ & (Decision & $<=$ & Low) \\
\hline 26 & If & (EC & $<=$ & Very low) & \& & (Slope & $<=$ & Moderate) & $\&$ & (IWQI & $<=$ & Very low) & & & & & $\Rightarrow>$ & (Decision & $<=$ & Low) \\
\hline 27 & If & (Slope & $<=$ & Low) & \& & (IWQI & $<=$ & Very low) & $\&$ & (ChangeLevel & $<=$ & High) & $\&$ & (Erosion & $<=$ & Moderate) & $\Rightarrow>$ & (Decision & $<=$ & Low) \\
\hline 28 & If & (NDVI & $<=$ & Low) & \& & (IWQI & $<=$ & Moderate) & & & & & & & & & $\Rightarrow>$ & (Decision & $<=$ & Moderate) \\
\hline 29 & If & (IWQI & $<=$ & Very low) & $\&$ & (ChangeLevel & $<=$ & Moderate) & & & & & & & & & $\Rightarrow>$ & (Decision & $<=$ & Moderate) \\
\hline 30 & If & (Slope & $<=$ & Low) & \& & (IWQI & $<=$ & Moderate) & $\&$ & (ChangeLevel & $<=$ & High) & & & & & $=>$ & (Decision & $<=$ & Moderate) \\
\hline 31 & If & (NDVI & $<=$ & Moderate) & \& & (EC & $<=$ & Moderate) & $\&$ & (Slope & $<=$ & High) & $\&$ & (IWQI & $<=$ & Moderate) & $\Rightarrow>$ & (Decision & $<=$ & Moderate) \\
\hline 32 & If & (NDVI & $<=$ & High) & \& & (EC & $<=$ & Moderate) & $\&$ & (Slope & $<=$ & Low) & $\&$ & (IWQI & $<=$ & High) & $\Rightarrow>$ & (Decision & $<=$ & Moderate) \\
\hline 33 & If & (NDVI & $<=$ & Moderate) & \& & (Slope & $<=$ & Low) & $\&$ & (IWQI & $<=$ & High) & $\&$ & (ChangeLevel & $<=$ & Moderate) & $\Rightarrow>$ & (Decision & $<=$ & Moderate) \\
\hline
\end{tabular}


Table 4 Refined If-Then rules from the linguistic land degradation datasets via RST using JMAF software for FIS implementation (Continued)

\begin{tabular}{|c|c|c|c|c|c|c|c|c|c|c|c|c|c|c|c|}
\hline 34 & If & (NDVI & $<=$ & High) & $\&$ & (IWQI & $<=$ & Low) & & & & $=>$ & (Decision & $<=$ & High) \\
\hline 35 & If & (IWQI & $<=$ & Moderate) & $\&$ & (ChangeLevel & $<=$ & Moderate) & & & & $\Rightarrow$ & (Decision & $<=$ & High) \\
\hline 36 & If & $(E C$ & $<=$ & Moderate) & $\&$ & (IWQI & $<=$ & Moderate) & $\&$ & (Erosion & $<=$ Moderate) & $=>$ & (Decision & $<=$ & High) \\
\hline 37 & If & (NDVI & $<=$ & High) & \& & (EC & $<=$ & Moderate) & $\&$ & (Erosion & $<=$ Moderate) & $=>$ & (Decision & $<=$ & High) \\
\hline 38 & If & (NDVI & $<=$ & Moderate) & \& & (EC & $<=$ & High) & $\&$ & (ChangeLevel & $<=$ Moderate) & $\Rightarrow>$ & (Decision & $<=$ & High) \\
\hline
\end{tabular}




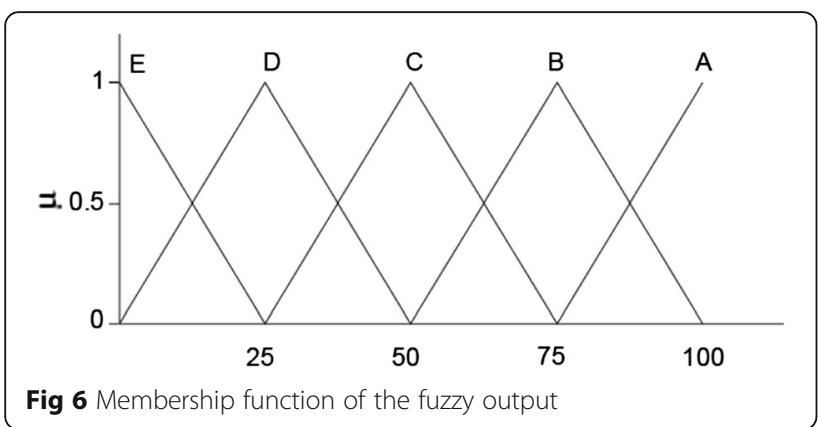

raster map, the pixels have values ranging from 0 to 0.843; pixels with higher values indicate very high susceptibility to land degradation. According to Table 5, the area belonging to susceptible parts, including high and very high classes, cover approximately 1831 ha of the whole area, and the classes belonging to "not susceptible" and "low susceptibility" cover 11010/50 ha. The major spatial distribution for each class is also presented in Table 5.

Field surveys and collecting samples of control points in parts of the region with different intensities of degradation was carried out for evaluation and validation of model results. Then the obtained results, the ground control points, were compared with susceptibility land degradation map from the RFIS model. In this way, the amount of their overlapping and conformity with land degradation susceptibility map were calculated. In other words, their overlapping percentage was considered as the model evaluation criteria that represent the accuracy of the model. For example, four ground control points along with their pictures which were taken in July, 2015 have been showed in the final map with a proper and understandable visual presentation (Fig. 8.). This result showed that there was $87 \%$ overlapping and this means that about $87 \%$ of taken ground control points were conformed to the land degradation susceptibility map.

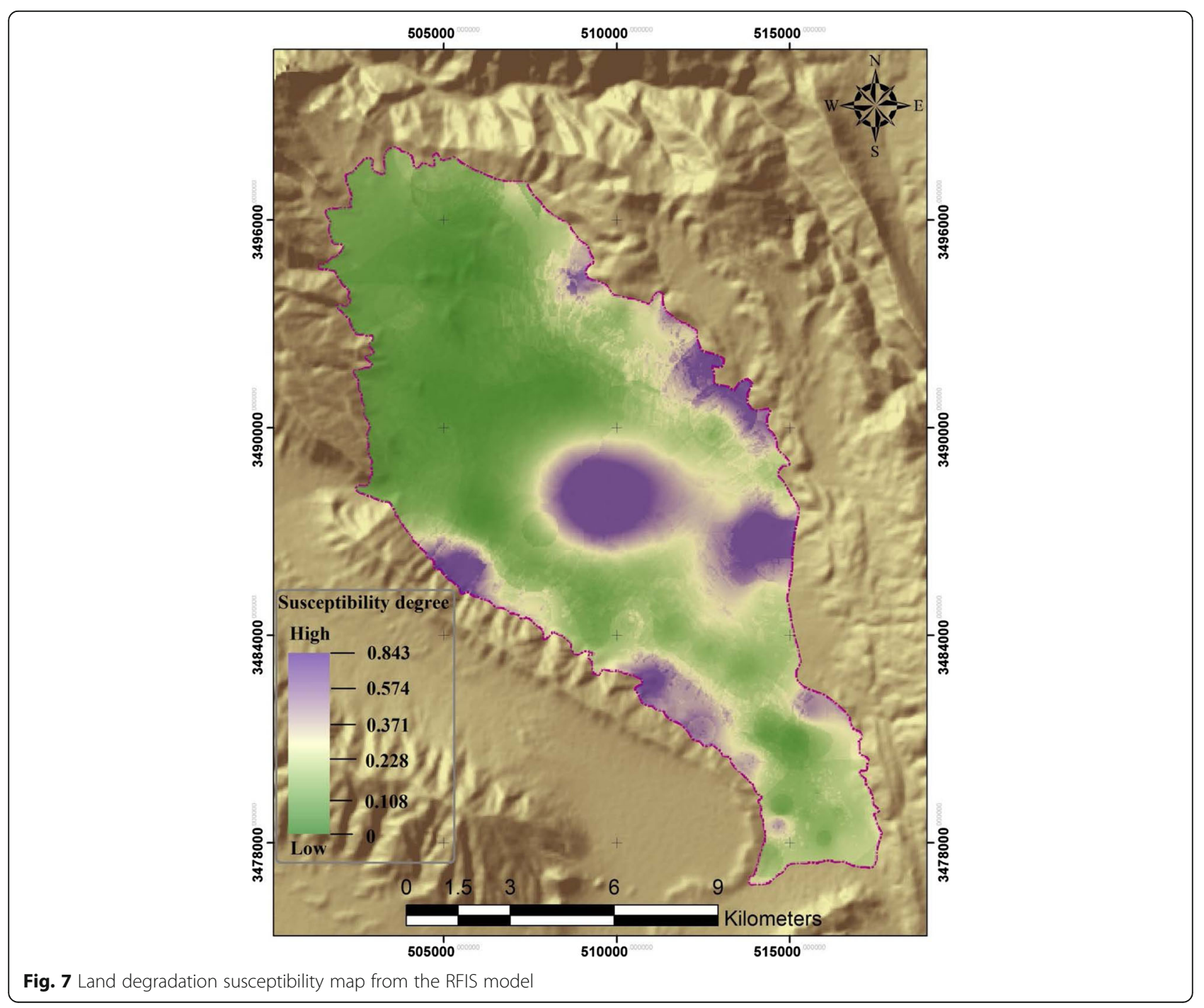


Table 5 Area distribution in different susceptible classes

\begin{tabular}{llll}
\hline \multirow{2}{*}{$\begin{array}{l}\text { Cusceptibility } \\
\text { Classes }\end{array}$} & Area & \multicolumn{2}{c}{ Major distribution } \\
\cline { 2 - 3 } & Ha & $\%$ & \\
\hline Very High & $492 / 00$ & $3 / 15$ & Center, east, and west \\
High & $1339 / 25$ & $8 / 60$ & Center and margins of plain \\
Moderate & $2752 / 75$ & $17 / 65$ & Center and margins of plain \\
Low & $4690 / 25$ & $30 / 10$ & Southeast and north margin \\
Not susceptibility & $6320 / 25$ & $40 / 50$ & Northwest and west \\
\hline
\end{tabular}

The results and evidences confirm the acceptable efficiency of GIS-integrated RST-FRBIS for land degradation susceptibility mapping.

To assess the influence of each parameter on the final map, we finally calculated the correlation coefficients between the land degradation susceptibility map and each input layer. The correlation $\left(\rho_{\text {final map, input }}\right)$ is a function of the covariance ( $\left.\operatorname{Cov}_{\text {final map, input }}\right)$ and standard deviations ( $\sigma_{\text {final map }}$ and $\left.\sigma_{\text {input }}\right)$.

$$
\rho_{\text {final map, input }}=\left(\operatorname{Cov}_{\text {final map, input }}\right) /\left(\sigma_{\text {final map }} \cdot \sigma_{\text {input }}\right)
$$

Table 6 reveals the influence of each layer on the final land degradation susceptibility map. According to Table 6, slope, and electrical conductivity of soil layers are most vigorously correlated with the final land degradation susceptibility map. RST results also have been shown the same correlations which fully accompany with the covariance and standard deviations results. The
RST can discover important facts hidden in datasets and express them with decision rules of natural language; and the results (rules) from a RST model are easily understood. This indicates that those places have the lowest quality soil (erosion and ECs), and the lowlands are seriously menaced by degradation.

The results of the land degradation susceptibility map in Fig. 7 indicate that the major parts of both the marginal and central parts of the Khanmirza agricultural plain have a high potential for land degradation. Generally, we can see unsuitable water quality for irrigation (IWQI), the resources for which are relatively fewer and more scattered throughout the marginal regions, due to intensive level changes of groundwater and aquifer depletion. Owing to lack of vegetation covering (bare lands) and considerably rill erosion in the parts of the margins of the region (especially in the east and west mountainside borders), these areas have been observed to be lands susceptible to degradation.

Overall, the statements above and field survey evidence confirm the acceptable efficiency of GISintegrated RST-FRBIS for land degradation susceptibility mapping. The Khanmirza agricultural plain highlights the facts that the lack of land and groundwater resources management and the continuing exploitation of resources can be causes of the intensification of land degradation. With the proposed approach, we clearly realized that the competence of the RST and FRBIS make this methodology suitable for land degradation susceptibility modeling.

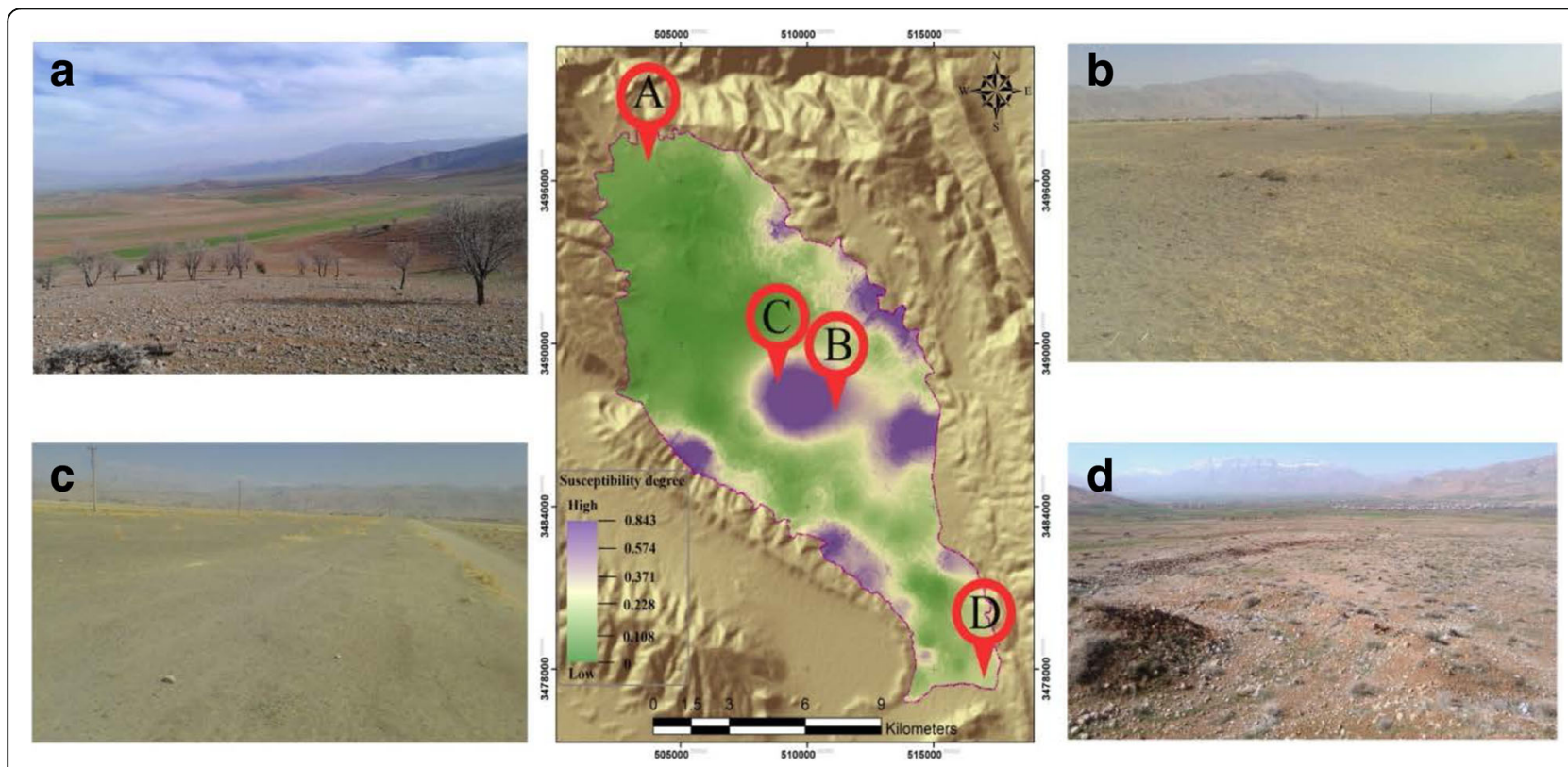

Fig. 8 Showing four geographical coordinates of ground control points along with their pictures and Land degradation susceptibility map; a \& d not susceptible to land degradation; b \& c High and very high susceptible to land degradation 
Table 6 Correlations between and degradation susceptibility and each factor map

\begin{tabular}{lc}
\hline Factors Map & Correlation coefficient \\
\hline Slope & 0.1912 \\
Soil erosion & 0.2675 \\
Groundwater level changes & 0.0081 \\
IWQI & 0.0582 \\
ECS & 0.1108 \\
NDVI changes & 0.0266 \\
\hline
\end{tabular}

\section{Conclusion}

The occurring causes of land degradation are complex, with various interactions among factors and properties in different parts of the world. Land degradation can be one of the consequences of low quality soil and water resources, which lead to the desertification phenomenon. The assessment and mapping of lands susceptible to degradation are important for combating desertification and for improving the use of natural resources. In order to facilitate modeling, this paper has proposed a new hybrid model (GIS-integrated Rough-FRBIS), based on this integrated method, to map areas susceptible to degradation using sort of layers such as the status of the groundwater resources, erosion and salinity of soil, slope, and vegetation cover changes. Rough and fuzzy sets are important techniques that can be used in various ways for modeling uncertainty in data and in spatial relationships between data entities. As a soft computing tool, rough set theory has become a powerful mathematical framework for pattern recognition, attribute value representation model to describe the dependencies among attributes, evaluate the significance of attributes, derivation of decision rules and knowledge discovery. This article displayed how to obtain a group of reasonable decision-rule sets by using the RST, and finally to solve the problems of obtaining the decision-rules in FRBIS. The results of the present study indicate that areas with the lowest quality in soil (soil erosion, ECs) are seriously menaced by degradation, especially in the center part and margins of the study area. The rural activities based on the agricultural economy that are pivotally responsible for initiating land salinization and exacerbating the degradation situation, which can be summed up as irrational and abusive land use practices, include developing agricultural wells, destroying meadow lands, and occupying national lands (marginal bare lands).

In spite of the existence of lands not susceptible to degradation in the northwestern and north-central parts of the Plain, it seems that the continued withdrawals of groundwater and mismanagement of soil resources will cause these areas to undergo land degradation in the near future. Moreover, the evidences reveal that the proposed hybrid model can acquire the advantages from the two methods (combining RST with FRBIS) and therefore, produce superlative results in modeling the land degradation susceptibility. Besides these findings, the proposed model can produce more reasonable and understandable rules, because the "if-then" rules produced by RST can model the qualitative aspects of human knowledge. The present work proposes for policy and decision-makers to use in their approach to land use and water management issues which will help them reach useful solutions within sustainable development approaches.

\section{Acknowledgements}

The authors would like to explicitly acknowledge due to all staff members of soil and water laboratory, faculty of natural resources at University of Tehran for lab analysis phase. Our gratitude further extends to the technical experts of Regional Water Company of Chaharmahal-Bakhtiari province for provide data and technical assistance.

\section{Competing interests}

The authors declare that they have no competing interests.

\section{Authors' contribution}

All authors read and approved the final manuscript.

\section{Author details}

${ }^{1}$ Faculty of Geography, University of Tehran, Tehran, Iran. ${ }^{2}$ Graduate Faculty of Environment, University of Tehran, Tehran, Iran.

Received: 10 September 2016 Accepted: 9 November 2016

Published online: 16 November 2016

\section{References}

Bajocco, S., A. De Angelis, L. Perini, A. Ferrara, and L. Salvati. 2012. The impact of land use/land cover changes on land degradation dynamics: a Mediterranean case study. Environmental Management 49(5): 980-989. doi:10. 1007/s00267-012-9831-8.

Bakr, N., D.C. Weindorf, M.H. Bahnassy, and M.M. El-Badawi. 2012. Multi-temporal assessment of land sensitivity to desertification in a fragile agro-ecosystem: environmental indicators. Ecological Indicators 15(1): 271-280. doi:10.1016/j. ecolind.2011.09.034.

Basso, F., E. Bove, S. Dumontet, A. Ferrara, M. Pisante, G. Quaranta, and M. Taberner. 2000. Evaluating environmental sensitivity at the basin scale through the use of geographic information systems and remotely sensed data: an example covering the Agri basin (Southern Italy). Catena 40(1): 19-35.

Bittner, T., and J. Stell. 2002. Approximate qualitative spatial reasoning. Spatial Cognition and Computation 2(4): 435-466.

Benabderrahmane, M.C., and H. Chenchouni. 2010. Assessing environmental sensitivity areas to desertification in Eastern Algeria using Mediterranean desertification and land use "MEDALUS" model. International Journal of Sustainable Water and Environmental System 1: 5-10. doi:10.5383/swes.01.01.002.5.

Change IC. 2001. Impacts, Adaptation and Vulnerability, Contribution of Working Group II to the Third Assessment Report of the Intergovernmental Panel on Climate Change, 1000. UK: Cambridge University Press.

Cheng, C.H., T.L. Chen, and L.Y. Wei. 2010. A hybrid model based on rough sets theory and genetic algorithms for stock price forecasting. Information Sciences 180(9): 1610-1629. doi:10.1016/j.ins.2010.01.014.

Crutzen, P.J. 2002. Geology of mankind. Nature 415(6867): 23-23. doi:10.1038/415023a.

d'Angelo, M., G. Enne, S. Madrau, L. Percich, F. Previtali, G. Pulina, and C. Zucca. 2000. Mitigating land degradation in Mediterranean agro-silvo-pastoral systems: a GISbased approach. Catena 40(1): 37-49. doi:10.1016/S0341-8162(99)00063-6.

Daftaribesheli, A., M. Ataei, and F. Sereshki. 2011. Assessment of rock slope stability using the fuzzy slope mass rating (FSMR) system. Applied Soft Computing 11(8): 4465-4473. doi:10.1016/j.asoc.2011.08.032.

de Paz, J.-M., J. Sánchez, and F. Visconti. 2006. Combined use of GIS and environmental indicators for assessment of chemical, physical and biological soil degradation in a Spanish Mediterranean region. Journal of Environmental Management 79(2): 150-162. doi:10.1016/j.jenvman.2005.06.002.

El Baroudy, A. 2011. Monitoring land degradation using remote sensing and GIS techniques in an area of the middle Nile Delta, Egypt. Catena 87(2): 201-208. 
Gao, J., and Y. Liu. 2010. Determination of land degradation causes in Tongyu County, Northeast China via land cover change detection. International Journal of Applied Earth Observation and Geoinformation 12(1): 9-16. doi:10. 1016/j.jag.2009.08.003.

Hansen P.M., Schjoerring J.K. 2003. Reflectance measurement of canopy biomass and nitrogen status in wheat crops using normalized difference vegetation indices and partial least squares regression. Remote Sensing of Environment 86:542-553.

Humphries, H.C., P.S. Bourgeron, and K.M. Reynolds. 2010. Sensitivity analysis of land unit suitability for conservation using a knowledge-based system. Environmental Management 46(2): 225-236. doi:10.1007/s00267-010-9515-1.

Iphar, M., and R. Goktan. 2006. An application of fuzzy sets to the diggability index rating method for surface mine equipment selection. International Journal of Rock Mechanics and Mining Sciences 43(2): 253-266.

Jianchu, X., J. Fox, J.B. Vogler, Z.P.F. Yongshou, Y. Lixin, Q. Jie, and S. Leisz. 2005. Land-use and land-cover change and farmer vulnerability in Xishuangbanna prefecture in southwestern China. Environmental Management 36(3): 404413. doi:10.1007/s00267-003-0289-6.

Komorowski, J., Z. Pawlak, L. Polkowski, and A. Skowron. 1998. Rough sets: a tutorial. In Rough-fuzzy hybridization: a New trend in decision-making, ed. S.K. Pal and A. Skowron, 3-98. Singapur: Springer Verlag. doi:10.1016/j.procs.2014.08.152.

Ladisa, G., M. Todorovic, and G. Trisorio Liuzzi. 2011. A GIS-based approach for desertification risk assessment in Apulia region. Italy: Physics and Chemistry of the Earth. doi:10.1016/j.pce.2011.05.007. Parts A/B/C.

Maerker, M., L. Angeli, L. Bottai, R. Costantini, R. Ferrari, L. Innocenti, and G. Siciliano. 2008. Assessment of land degradation susceptibility by scenario analysis: a case study in southern Tuscany, Italy. Geomorphology 93(1): 120129. doi:10.1016/j.geomorph.2006.12.020.

Mamdani, E.H., and S. Assilian. 1975. An experiment in linguistic synthesis with a fuzzy logic controller. International Journal of Man-Machine Studies 7(1): 1-13. doi:10.1016/S0020-7373(75)80002-2.

Märker, M., L. Angeli, L. Bottai, R. Costantini, R. Ferrari, L. Innocenti, and G. Siciliano. 2008. Assessment of land degradation susceptibility by scenario analysis: a case study in Southern Tuscany, Italy. Geomorphology 93: 120-129.

Metzger, M., M. Rounsevell, L. Acosta-Michlik, R. Leemans, and D. Schröter. 2006. The vulnerability of ecosystem services to land use change. Agriculture Ecosystems \& Environment 114(1): 69-85. doi:10.1016/j.agee.2005.11.025.

Monjezi, M., and M. Rezaei. 2011. Developing a new fuzzy model to predict burden from rock geomechanical properties. Expert Systems with Applications 38(8): 9266-9273. doi:10.1016/j.eswa.2011.01.029.

Motiee Langroodi, S.H., M. Ghadiri Masoum, H. Nasiri, and Javi S. Taghipour. 2015. Spatial and temporal variability analysis of groundwater quantity to land use/ land cover change in the Khanmirza agricultural plain, Iran. Arabian Journal of Geosciences 8(10): 8385-8397. doi:10.1007/s12517-015-1786-7.

Moukana, J.A., and K. Koike. 2008. Geostatistical model for correlating declining groundwater levels with changes in land cover detected from analyses of satellite images. Computational Geosciences 34(11): 1527-1540.

Papadopoulos, A., D. Kalivas, and T. Hatzichristos. 2011. Decision support system for nitrogen fertilization using fuzzy theory. Computers and Electronics in Agriculture 78(2): 130-139. doi:10.1016/j.compag.2011.06.007.

Pavel J, and Jiři K. 2007. Classification model based on rough and fuzzy sets theory. In: 6th WSEAS international conference on Computational intelligence, man-machine systems and cybernetics. 199-203. Puerto De La Cruz, Tenerife. Spain. https://www.researchgate.net/publication/228398990_ Classification_model_based_on_rough_and_fuzzy_sets_theory.

Pawlak Z. 1982. Rough sets. International Journal of Computational Information Science. 341-356. doi: 10.1007/BF01001956.

Pawlak, Z., and A. Skowron. 2007. Rough sets and boolean reasoning. Information Sciences 177: 41-73. doi:10.1016/j.ins.2006.06.007.

Pawlak, Z. 2001. A primer on rough sets: a new approach to drawing conclusions from data. The Dynamics of Judicial Proof 94: 135-142. doi:10.1007/978-37908-1792-8_7.

Ponce, J., and A. Karahoca. 2009. Data mining and knowledge discovery in real life applications. Vienna: I-Tech. doi:10.5772/62143.

Rasmy, M., A. Gad, H. Abdelsalam, and M. Siwailam. 2010. A dynamic simulation model of desertification in Egypt. The Egyptian Journal of Remote Sensing and Space Science 13(2): 101-111. doi:10.1016/j.ejrs.2010.03.001.

Regional Water Company of Chaharmahal-Bakhtiari province. 2010. Analysis of water resources 2: 35-50

Reshmidevi, T., T. Eldho, and R. Jana. 2009. A GlS-integrated fuzzy rule-based inference system for land suitability evaluation in agricultural watersheds. Agricultural Systems 101(1): 101-109. doi:10.1016/j.agsy.2009.04.001.
Reynolds, J.F., D.M.S. Smith, E.F. Lambin, B. Turner, M. Mortimore, S.P. Batterbury, T.E. Downing, H. Dowlatabadi, R.J. Fernández, and J.E. Herrick. 2007. Global desertification: building a science for dryland development. Science 316(5826): 847-851. doi:10.1126/science.1131634.

Ross TJ. 2009. Fuzzy logic with engineering applications. Wiley. doi: 10.1002/ 9781119994374

Salvati, L., and M. Carlucci. 2010. Estimating land degradation risk for agriculture in Italy using an indirect approach. Ecological Economics 69(3): 511-518. doi: 10.1016/j.ecolecon.2009.08.025.

Salvati L, Tombolini I, Perini L,and Ferrara A. 2013. Landscape changes and environmental quality: the evolution of land vulnerability and potential resilience to degradation in Italy. Regional Environmental Change:1-11. doi: 10 1007/s10113-013-0437-3

Salvati, L., and M. Zitti. 2008. Regional convergence of environmental variables: empirical evidences from land degradation. Ecological Economics 68(1): 162-168. doi:10.1016/j.ecolecon.2008.02.018.

Sepehr, A., A.M. Hassanli, M. Ekhtesasi, and J. Jamali. 2007. Quantitative assessment of desertification in south of Iran using MEDALUS method. Environmental Monitoring and Assessment 134(1-3): 243-254. doi:10.1007/ s10661-007-9613-6.

Sepehr, A., and C. Zucca. 2012. Ranking desertification indicators using TOPSIS algorithm. Natural Hazards 62(3): 1137-1153. doi:10.1007/s11069012-0139-z.

Shahbazi, F., A.A. Jafarzadeh, and M.R. Shahbazi. 2009. Agro-ecological field vulnerability evaluation and climate change impacts in Souma area (Iran), using MicroLEIS DSS. Biologia 64(3): 555-559. doi:10.2478/s11756-009-0104-9.

Shi W, Wang S, Li D, and Wang X. 2003. Uncertainty-based Spatial Data Mining. In: Proceedings of Asia GIS Association, 124-135. Wuhan.

Statistical Yearbook of Chaharmahal-Bakhtyari Province, 2010. Website of Statistical Center of Iran (In Persian): http://amar.org.ir/Default.aspx?tabid= 667\&fid $=7298$

Taghipour Javi, S., B. Malekmohamadi, and H. Mokhtari. 2014. Application of geographically weighted regression model to analysis of spatiotemporal varying relationships between groundwater quantity and land use changes (case study: Khanmirza Plain, Iran). Environmental Monitoring and Assessment 186(5): 3123-3138. doi:10.1007/s10661-013-3605-5.

Taghipour Javi, S., H. Mokhtari, A. Rashidi, and Javi H. Taghipour. 2015. Analysis of spatiotemporal relationships between irrigation water quality and geoenvironmental variables in the Khanmirza Agricultural Plain, Iran. Journal of Biodiversity and Environmental Sciences 6(6): 240-252.

Taghipour Javi, S., A. Fazeli, and B. Kazemi. 2016. A case study of desertification hazard mapping using the MEDALUS (ESAs) methodology in southwest Iran. Journal of Natural Resources and Development 6: 1--8. doi:10.5027/jnrd.v6i0.01.

Takagi, T., and M. Sugeno. 1985. Fuzzy identification of systems and its applications to modeling and control, 116-132. Man and Cybernetics: Systems. doi:10. 1109/TSMC.1985.6313399.

Tsukamoto, Y. 1979. An approach to fuzzy reasoning method. Advances in fuzzy set theory and applications 137: 149.

Vågen, T.-G., L.A. Winowiecki, A. Abegaz, and K.M. Hadgu. 2013. Landsat-based approaches for mapping of land degradation prevalence and soil functional properties in Ethiopia. Remote Sensing of Environment 134: 266-275. doi:10. 1016/j.rse.2013.03.006.

Wessels, K., F. Van den Bergh, and R. Scholes. 2012. Limits to detectability of land degradation by trend analysis of vegetation index data. Remote Sensing of Environment 125: 10-22. doi:10.1016/j.rse.2012.06.022.

Yazdani-Chamzini, A., A. Jamshidi, S.H. Yakhchali, and S. Khaleghi. 2013. Developing a new fuzzy inference system for pipeline risk assessment. Journal of Loss Prevention in the Process Industries 26: 197-208. doi:10.1016/j. jlp.2012.10.010.

Yazdani-Chamzini, A., and S.H. Yakhchali. 2012. Tunnel boring machine (TBM) selection using fuzzy multicriteria decision making methods. Tunnelling and Underground Space Technology 30: 194-204. doi:10.1016/j.tust.2012.02.021.

Zadeh, L.A. 1965. Fuzzy sets. Information and Control 8(3): 338-353. doi:10.1016/ S0019-9958(65)90241-X.

Zagarell A. 1982. Prehistory of the Northeast Bahtiyari Mountains. Iran: The Rise of a Highland Way

Zaitchik, B.F., J.P. Evans, and R.B. Smith. 2007. Regional impact of an elevated heat source: the Zagros Plateau of Iran. Journal of Climate 20(16): 4133-4146. http://dx.doi.org/10.1175/JCLI4248.1.

Zhang, J., T. Li, and H. Chen. 2014. Composite rough sets for dynamic data mining. Information Sciences 257: 81-100. doi:10.1016/j.ins.2013.08.016. 